\title{
Boundaries And Applications: The Teacher Quality Debate In America
}

Matthew R. Hodgman, College of William \& Mary, USA

\begin{abstract}
The teacher quality debate in America remains an important one. Many feel that teachers are leaving teacher preparation programs without the appropriate knowledge and skills to be effective classroom practitioners. School districts have spent a considerable amount of time and economic resources addressing the teacher quality provisions of No Child Left Behind legislation, yet there is still substantial disagreement as to what exactly "teacher quality" is and how "quality" teachers can be developed and convinced to teach in schools that need them most. This article describes the current parameters and arguments surrounding the teacher quality debate in America and makes suggestions as to how teacher quality and teaching quality can be improved. Two major aims of the article are to explore how teacher quality can be assessed and articulate how schools can implement reasonable systems to attract quality teachers. This article argues that a bold, balanced, and open-minded systemic approach to reform is most likely to provide a productive definition of teacher quality and allow schools to attract, develop, and retain quality teacher candidates.
\end{abstract}

Keywords: Teacher Quality; Systemic Reform; No Child Left Behind; Teacher Preparation Programs

\section{INTRODUCTION}

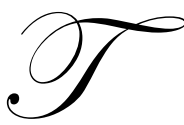

here is concurrence among educators that teacher quality is the single most important school-related factor influencing student achievement (Gabriel, 2005; Izumi \& Evers, 2002; Rice, 2003; Stronge, Gareis, \& Little, 2006). Despite this agreement, the specific characteristics that constitute teacher quality are hotly debated as mixed research findings present policy issues for education leaders. School districts have spent a considerable amount of time and economic resources addressing the teacher quality provisions of No Child Left Behind (NCLB) legislation, yet there is still substantial disagreement as to what exactly "teacher quality" is and how "quality" teachers can be attracted, developed, and retained (Rice, 2003; Stronge et al., 2006).

Questions concerning teacher quality need to be asked at all levels of education and throughout all sectors. Germane questions relative to the teacher quality debate include:

1. Can teacher quality narrow achievement gaps along racial and socioeconomic lines?

2. How does teacher quality manifest in hiring decisions?

3. How can teacher quality be assessed in practicing teachers working at all levels of education?

4. How can practicing teachers assess their own levels of teacher quality?

5. How can teacher and teaching quality be improved in non-profit and for-profit education sectors?

6. How can schools implement reasonable teacher compensation systems to attract and retain quality teachers?

In light of these questions, education leaders are hoping to make well-informed decisions relative to teacher hiring and retention as statistics show troubling trends in the teaching profession. High teacher turnover, teacher shortages, poor distribution of credentialed teachers, and noted failures of traditional teacher preparation programs need to be addressed (Boggess, 2008). Key players, including teachers, policy-makers, administrators, parents, researchers, reformers, and community members, are having difficulty finding common ground on where to locate the teacher quality debate although prominent debate entry points consistently revolve around issues connected to teacher supply and demand, preparation, and retention. 
In terms of supply and demand, there is a concern that the teaching profession is not attracting the "right" candidates. Factors influencing definitions of "right" include teacher personality characteristics, overall academic credentials, content knowledge, racial diversity, and level of commitment to serve in high-poverty areas (Liston, Borko, \& Whitcomb, 2008).

Relative to the preparation faction of the debate, some feel that teachers are leaving teacher preparation programs without the appropriate knowledge and skills to be effective classroom practitioners. The critique on traditional teacher preparation programs is that they have low admissions standards, curricular fragmentation, excessive requirements, and disconnection with classroom teaching (Liston et al., 2008). In order to address perceived traditional teacher preparation deficits, alternate certification routes (ACRs) are growing rapidly as approximately one third of new-to-the-profession teachers hired by school districts come through ACRs (Feistritzer, 2008, p. 1).

Those who locate the teacher quality debate as a retention issue cite low teacher salaries, few advancement opportunities, and lack of teacher support mechanisms as reasons why teachers leave the field. Teacher salaries undoubtedly play a significant role in high teacher turnover as fewer occupations requiring college degrees have salaries lower than those found in teaching with average teacher salaries starting at $\$ 30,719$ (Stronge et al., 2006, p. 17). Now that the issues, players, questions, and sides of the teacher quality issue have been defined, it is appropriate to look more specifically at the major arguments.

\section{THE ARGUMENTS}

The most prominent argument surrounding "teacher quality" involves defining the term. Most agree that "highly qualified" as defined by NCLB is only a starting point in the discussion of defining teacher quality and that gains in student achievement should be the ultimate goal of any school (Izumi \& Evers, 2002; Ladson-Billings, 2005/2006; Stronge et al., 2006). Strict supporters of NCLB terminology measure teacher quality by objective inputs such as certification of content knowledge, academic degrees, years of teaching experience, grade point averages, and college entrance exam results. Those in favor of utilizing objective inputs when assessing teacher quality point to research linking objective inputs and student achievement. Research indicates that teacher experiences, advanced degrees in math, math/science certification, pedagogy-intensive coursework, and literacy-based standardized test results are indictors that have positive effects on student performance (Rice, 2003).

Others feel that subjective inputs such as interpersonal skills, professionalism, perseverance, reflection on practice, and willingness to address societal power issues are the best predictors of teacher quality. Proponents of using subjective measurements to gauge teacher quality feel that subjective traits are less teachable than objective inputs. There is research indicating that principals do not consistently value objective inputs when making hiring decisions instead preferring subjective inputs such as perceived prestige of academic institutions attended and the degree to which the teacher candidate was local and personally known by the principal (Brisson, 2008). Despite these hiring preferences, it is important to note that subjective inputs of quality need to be assessed in terms of how they translate to effective teaching practice in classroom settings upon hire (Rice, 2003).

Other prominent definitions of teacher quality make distinctions between "teacher quality" and "teaching quality." These distinctions suggest that in-service teachers and pre-service teachers at the time of initial hire should be judged by different criteria. Where teacher quality speaks more to the knowledge, skills, and dispositions of teachers, teaching quality is the degree to which teachers make use of their knowledge and skills in practice. Teaching quality involves gains in student achievement and is often directly impacted by the degree of support school districts afford their teachers. Thus, it is possible that a quality teacher may not become a successful practitioner if school instructional resources, staffing levels, opportunities for professional development, and support mechanisms are depleted. The role of school and community forces in shaping teachers' practices and student learning cannot be underemphasized (Mitchell, Robinson, Plake, \& Knowles, 2001).

Beyond the initial debate as to what constitutes teacher quality, educational leaders have spent significant time discussing how quality teachers can be attracted, developed, and retained. The question of development hinges around teacher preparation, certification, and professional development. There is growing concern that traditional 
university-based teacher preparation programs are not producing competent and effective teachers in classroom settings. In addition, credentialed teachers are not being equitably distributed throughout underachieving schools thus creating a teacher quality gap. In response to these concerns, ACRs have become increasingly popular (Boggess, 2008). Cities such as Boston and Chicago have taken to training their own new teachers through partnerships with teacher residency apprenticeship programs. Supporters of ACRs believe that although traditional teacher preparation programs should not be completely eliminated, ACRs may be more adaptable models where instruction can be adjusted to the specific needs of ACR candidates and the needs of the districts in which these candidates hope to teach (Feistritzer, 2008).

Further questions surrounding teacher development focus on professional development opportunities. In terms of professional development, many believe that reflection, feedback, and alignment with school goals should be hallmarks of meaningful development agendas. Reflection can be defined as looking at one's experiences, making connections with one's thoughts, and utilizing these connections in action (Haciomeroglu, 2009). Supporters of reflection in teacher professional development believe reflection can be used by teachers to change teaching approaches that are not working and to better integrate theory and practice (Haciomeroglu, 2009).

Many also believe that professional teacher development efforts should include substantive feedback from administrators, teachers, and students alike. As Frase and Conley (1994) argue, constructive feedback needs to be given by well trained evaluators who maintain positivity in their comments and align criticism with student-centered school goals (p. 69). Too often feedback is used to intimidate teachers instead of focusing on appropriate larger school goals and issues within a teacher's control. Positive feedback given by teachers, administrators, and students is more likely to provide a clearer picture of what teachers may or may not be doing well.

A final large component of the teacher quality debate involves attracting and retaining quality teachers. Participants in this debate are divided as to whether extrinsic or intrinsic incentives are more likely to lure and keep teachers in the profession. On one side, extrinsic benefits are important. As Stronge et al. (2006) have pointed out, teacher compensation systems need to be linked with teacher quality. In addition, such systems should possess aspects of competitiveness, flexibility, comprehensiveness, clarity, and appropriateness (Stronge et al., 2006, p. 32). Clearly, more competitive salaries are more likely to attract teachers, but will higher salaries alone retain teachers for years to come?

Those who argue for the importance of intrinsic incentives believe that teachers need to work in positive, nurturing, and productive environments in order to remain committed to teaching. Intrinsic rewards may include: how teachers feel at work, how they are treated, teacher ownership of their craft, opportunities for collaboration, and a rich intellectual environment (Kenny, 2010).

\section{CONCLUSION}

In conclusion, based on the arguments above, it is apparent that a bold, balanced, and open-minded systemic approach to reform is most likely to provide a productive definition of teacher quality and allow schools to attract, develop, and retain quality teacher candidates. Systemic reform efforts spawn from a close alignment among the parts of the education system (administrators, teachers, parents, the community, etc.) and these parts must address quality-related issues in concert.

In terms of defining teacher quality, student achievement should be the primary concern of schools and those who work there. Beyond that, teacher quality needs to encompass both objective and subjective components. Those with hiring power should use objective inputs of teacher quality for screening purposes only. Once an applicant has been screened for appropriate levels of certification, schooling, and test outcomes, a second phase of subjective scrutiny should ensue. This would involve assessing the degree to which applicants demonstrate important interpersonal skills, the ability to reflect and learn from past experiences, and a strong willingness to meet student, school, and community needs. Hiring agents should also learn more about how an applicant's objective credentials translate into effective classroom practice. Once this information is gleaned and deemed acceptable, a job offer should be made to an applicant. Throughout this analysis, hiring agents should not make conclusions simply based on where an applicant went to school or how he or she earned content certification. Thus, teacher quality 
involves a mix of objective and subjective inputs with a clear focus on practical application, larger community needs, and student achievement.

After hiring decisions are made, school administrators and faculty should work with novice teachers to ensure they are supported and assessed fairly within the confines of available resources. Teachers should be offered both intrinsic and extrinsic incentives to remain in the profession. This means that starting salaries would be competitive and teachers would be economically rewarded for demonstrating aspects of teacher quality through continuous dedication to student needs and school goals. Intrinsically, a positive school culture should be fostered; this means that the school environment must be a place where teachers feel valued, can connect reflection meaningfully to practice, and have real power to promote change. Constructive professional development opportunities must exist and teachers must receive meaningful feedback connected to school goals and be allowed to translate that feedback into enhanced practice. A positive and open-minded culture, such as this, must be supported economically and intellectually by administrators, policy makers, the public, and other teachers.

Finally, schools must be creative, bold, and reflective about teacher quality reform. Current policies need to be constantly reviewed and mission statements updated if necessary. New ways of securing funding, reinventing curriculum, and promoting a positive work environment need to be investigated and implemented while keeping in mind that teachers are every school's greatest resource and student learning every school's primary focus.

\section{AUTHOR INFORMATION}

Matthew R. Hodgman is a PhD candidate in Higher Education Administration at the College of William and Mary where he also holds the position of Graduate Assistant for Student Conduct. Previously, Mr. Hodgman served as an adjunct professor of general education at Westwood College and as an instructor at Chyten Educational Services. He holds degrees from Georgetown, Johns Hopkins, George Washington, and the University of Pennsylvania. He resides in Williamsburg, Virginia. E-mail: mrhodgman@email.wm.edu

\section{REFERENCES}

1. Boggess, L. (2008, October 30). Character and critique: District constructions of teacher quality. Paper presented at the annual meeting of the UCEA Convention, Orlando, FL. Retrieved June 4, 2011 from http://www.allacademic.com/meta/p274561_index.html

2. Brisson, T. L. (2008, October 30). Are school leaders effectively prepared to identify teacher quality? Paper presented at the annual meeting of the UCEA Convention, Orlando, FL. Retrieved June 14, 2011 from http://www.allacademic.com/meta/p274728_index.html

3. Feistritzer, C.E. (2008). Building a quality teaching force: Lessons learned from alternate routes. Boston: Allyn \& Bacon.

4. $\quad$ Frase, L.E., \& Conley, S.C. (1994). Creating learning places for teachers, too. Thousand Oaks: Corwin Press.

5. Gabriel, J.G. (2005). How to thrive as a teacher leader. Alexandria: ASCD.

6. Haciomeroglu, G. (2009, September 23). Preservice teachers' reflections on their instructional practices. Paper presented at the annual meeting of the North American Chapter of the International Group for the Psychology of Mathematics Education, Atlanta, GA. Retrieved June 10, 2011 from http://www.allacademic.com/meta/p370022 index.html

7. Izumi, L. T., \& Evers, W.M. (Eds.). (2002). Teacher quality. Stanford: Hoover Institution Press.

8. Kenny, D. (2010, September 22). A teacher quality manifesto. The Wall Street Journal. Retrieved from http://online.wsj.com/article/SB10001424052748703440604575496281030445268.html

9. Ladson-Billings, G. (2005/2006, Winter). Teacher quality: Conversations on quality.[Transcript]. Retrieved from http://www.learningforward.org/news/jsd/koppich212.cfm

10. Liston, D., Borko, H., \& Whitcomb, J. (2008, March/April). The teacher educator's role in Enhancing teacher quality. Journal of Teacher Education, 59 (2), 111-116. doi: 10.1177/0022487108315581.

11. Mitchell, K. J., Robinson, D. Z., Plake, B. S. \& Knowles, K. T. (Eds.). (2001). Testing teacher candidates: The role of licensure tests in improving teacher quality. Washington, D.C.: National Academy Press. 
12. Rice, J.K. (2003). Teacher quality: Understanding the effectiveness of teacher attributes. Washington, D.C.: Economic Policy Institute.

13. Stronge, J. H., Gareis, C.R., \& Little, C.A. (2006). Teacher pay and teacher quality: Attracting, developing, and retaining the best teachers. Thousand Oaks: Corwin Press. 
NOTES 